\title{
Synthetic socioeconomic based domestic wastewater hydrographs for small arid communities
}

\author{
H. Elnakar, E. Imam \& K. Nassar \\ Department of Construction and Architectural Engineering, \\ The American University in Cairo, Egypt
}

\begin{abstract}
A model was developed to predict synthetic socioeconomic based domestic wastewater hydrographs for the small arid communities. The model predicts the flow hydrograph for random weekdays and weekends based on the specific socioeconomic characteristics of the community. The main socioeconomic characteristics are the composition of the community, the different user behaviours in using water appliances, and the unit discharges of such appliances. Use patterns of water appliances are assumed to vary for the various members of the community and the type of day. Each community is composed of several social categories such as the employee, working woman, stay home woman, stay home child, students etc. The use patterns account for the stochastic nature of use in terms of number of uses, duration of the use and times of use in the day. Randomly generated hydrographs are generated for weekdays and weekends along with synthetic hydrographs of non-exceedance. The model was verified for a small residential compound in Sharm El Shiekh - Egypt using 11 days of flow measurements performed in summer. The synthetic hydrographs based on assumed water use patterns of the various members of the community compared reasonably with the measured hydrographs. Synthetic hydrographs can be derived for a community under consideration to reflect its socioeconomic conditions and thus can be used to generate probability based peaking factors to be used in the design of sewerage systems pumping facilities, and treatment plants.

Keywords: socioeconomic hydrographs, stochastic flows, small arid communities, peaking flow factors, wastewater treatment plant influent.
\end{abstract}




\section{Introduction}

Wastewater from kitchens, bathrooms, laundries and toilets ends up in the sewer network, pumping stations and finally the treatment plant. All these elements should be designed to handle their critical design flows. For sewers and pumping stations, peak hourly flows are critical whereas for the various units of the treatment plant other flows that would be sustained for different residence times are critical to their design.

Design codes for different localities usually include formulas to compute critical design flows using average unit flow of wastewater generated from a community and an appropriate peaking factor $[1,2]$. These codes usually refer to a system capacity based on the average unit sewage flow related to the level of water use in the community which might vary based on the nature of the community (urban, rural, arid climate with limited water resources or temperate climate, etc.). Peaking factors usually suggested by design codes are related to the population or daily flow rate without considering the socioeconomic status and the water use behaviour of the community.

Geyer and Lentz [3] developed a regression equation that demonstrates that the average per capita wastewater flow increases with the increase of average market value of the residence place. In addition, they presented the daily peaking factors for different communities at different probabilities without defining the socioeconomic characteristics of these communities [3]. Butler and Graham developed a model to predict wastewater hydrographs at dry weather flow conditions that accounts for the wastewater inflow and the routing in the sewer network [4]. They presented the term "Expected Flow" as the product of the number of appliances connected to a node, the average dwelling occupancy, and the sum of all appliances of the product of the probability of using an appliance, the discharge of the appliance and the fraction of appliances upstream from the node at a time [4]. The probability of using an appliance was assumed to be the product of the time of use of a certain appliance and its frequency of use [4]. The model developed by Butler and Graham utilized the data collected by Butler [5] that were collected in the form of the frequency of use of water closets, wash basins, sinks, baths, showers and washing machines and the discharge characteristics of these appliances in terms of duration of use and volume. These data were collected as average values with a range for all user types without classifying the user types in terms of male or female, work style, age and others. Imam and Elnakar [6] combined limited hourly measurements and long term daily measurements to derive statistically sustained flow factors for different time durations: instantaneous, 1 hour, 2 hour, etcetera up to 24 hours.

The objective of this paper is to develop synthetic socioeconomic based domestic wastewater hydrographs for small arid communities based on the specific socioeconomic characteristics of the community. These hydrographs can be used in deriving flow factors for a community with certain population composition and socioeconomic status for different sustained durations and probabilities of non exceedance. 


\section{Model development}

Daily dry-weather wastewater hydrographs generated from a certain small arid community will be synthesized based on the use of the various members of the community of fixtures and appliances at homes, and other buildings. The community is divided into various categories; each with a similar water use pattern. The water use pattern for each category will be assumed to vary from a weekday, a weekend, a holiday or a special event. The water use pattern will account for the stochastic use of fixtures and appliances among members of the same category, day-to-day use by the same person, and the generated wastewater flow for the same type of fixture. The model can generate the synthetic hydrograph at different locations (nodes) in the sewerage system by considering the fraction of community population existing upstream of the node. For small communities, the effect of hydrograph shift and distortion due to storage and travel time will be assumed negligible due the small size of the community and its sewerage network.

\subsection{Community composition}

A community is composed of a number of social categories $(\mathrm{k})$; each with a similar water use pattern on a certain day type (d): working men, working women, stay-at-home women, students and school children, stay-at-home children and senior citizens. The number of persons in any category $l(l=1,2, . \mathrm{k})$ will be estimated as a fraction of the total community population from a number of people with different water use repetitive patterns $\left(1_{1}, 1_{2}, 1_{3} \ldots \mathrm{k}\right)$. Each residential community may be composed of percentiles of the working style such as the work shifts and the location of the work whether it is in city or out of city has an impact on the wastewater hydrographs generated from each community. The number of people $\left(\mathrm{N}_{\mathrm{d}, 1}\right)$ with the same pattern is a percentage of the total population $(\mathrm{P})$, eqn. (1)

$$
N_{l, d}=C_{l, d} P_{l}
$$

where: $\mathrm{N}_{1, \mathrm{~d}}=$ the number of people with the same pattern at day type (d) either weekend or weekday; $\mathrm{P}$ =the total population contributing to the node under consideration; and $\mathrm{C}_{1, \mathrm{~d}}=$ fraction of the population with the same water use pattern on day $(d)$.

\subsection{Water use pattern user profile for each appliance}

The generated wastewater hydrograph on a typical day (d) from an individual of a category (1) of the community will be assumed to be the sum of discharges from the various fixtures and appliances at the same corresponding times of the day. The water use pattern of a certain fixture or appliance is characterized by the number of uses, the times of the use during the day, and the duration of use. Obviously, the human behaviour is not repetitive as identical daily cycles; therefore the above variables will be treated as normally distributed random variables. Such water use pattern of a certain fixture/appliance can be monitored 
for each category and day of use for a community with certain socioeconomic status.

Figure 1 shows a typical water use pattern of a fixture of an individual of category (l) on a typical day with type $(d)$. It shows the probability density $f(t)$ that the person is using the $\mathrm{WC}$ at the shown times of the day. The use pattern shows four uses of the WC with their probability -time of use curves. Each single use has an expected time and its variance which may vary from one to the other. Equation (2) gives the probability density function of the normally distributed time of use

$$
f(t)=\frac{1}{\sigma \sqrt{2 \pi}} e^{-\frac{1}{2}\left(\frac{t-\mu}{\sigma}\right)^{2}}
$$

where: $\mu$ is the time at which the appliance (i) is most likely to be used by an individual of category (1); $\sigma$ is the standard deviation for the time of use.

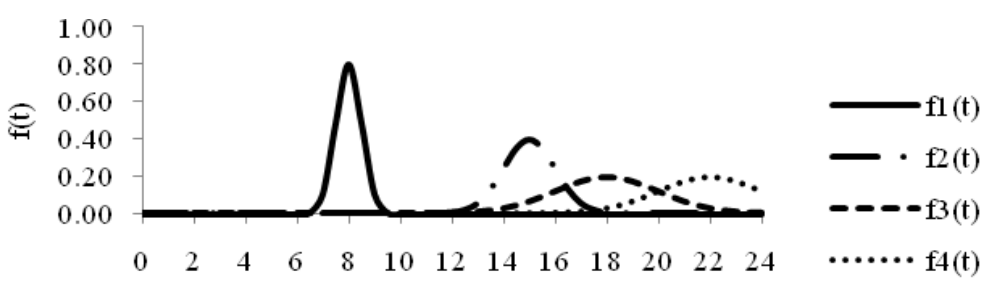

Time

Figure 1: $\quad$ Normal probability distribution of using a water appliance $\mathrm{f}(\mathrm{t})$.

When the probability distributions of two or more uses by the same person intersect, then the probability is estimated by eqn. (3) and is graphed in Figure 2. If a number of use activities (r) will be intersected, the probability $\mathrm{f}(\mathrm{t})$ at any time (t) will be then the sum of these activities, eqn. (3) and Figure 2.

$$
f(t)=\left[\sum_{y=1}^{r} f_{y}(t)-\sum_{y=1}^{r} \sum_{z=y+1}^{r} f_{y}(t) f_{z}(t)+r \prod_{y=1}^{r} f_{y}(t)\right] / r
$$

Figure 3 shows the water use pattern of an individual in category i.e. the probability density $f(t)$ that the person shall the appliance at time $t$. To estimate the probability $\mathrm{p}(\mathrm{n})$ that several individuals $(\mathrm{n})$ of the total individuals $\left(\mathrm{N}_{1, \mathrm{~d}}\right)$ of category (1) might use the appliance at time ( $\mathrm{t}$ ), the binomial distribution is used as shown in eqn. (4).

$$
p(n)=\frac{N !}{n !(N-n) !} f(t)^{n}(1-f(t))^{N-n}
$$

The expected number of people $\mathrm{E}(\mathrm{n})$ who are using an appliance is also given by the binomial distribution, eqn. (5).

$$
E(n)_{d, L, i, t}=N_{d, L, i} * p(n)_{d, L, i}
$$




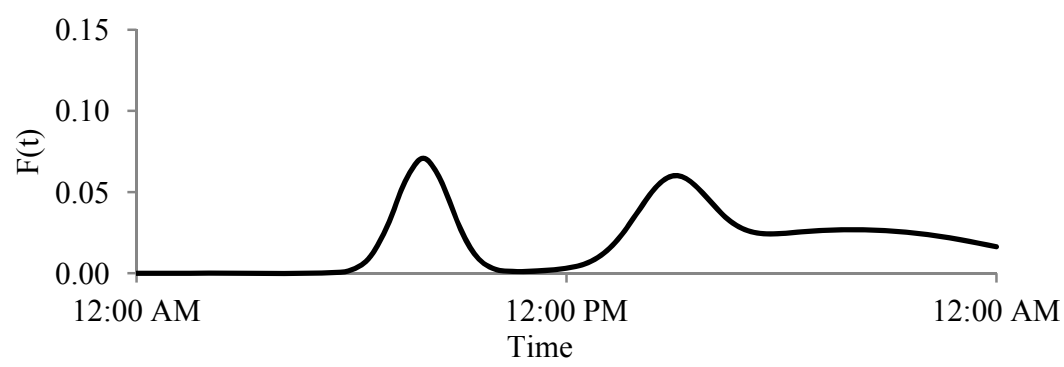

Figure 2: $\quad$ Probability distribution of using a water appliance $\mathrm{f}(\mathrm{t})$.

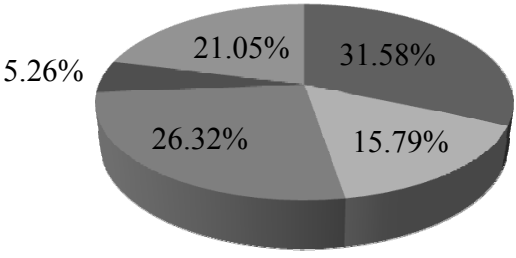

Employee (11)

After Noon Workers (12)

- Stay Home Mom (13)

- Working Woman (14)

- Stay Home Child (15)

Figure 3: $\quad$ Social categories of DAR.

\subsection{Wastewater generated when using an appliance and at nodes}

Equation (5) gives the expected number of individuals (n) out of the total number of individuals $\left(\mathrm{N}_{1}\right)$ of category (l) who might be using appliance (i) at a certain time (t) of a typical day (d). To account for the various sources of variability in the generation of wastewater from the community, the number of uses $\left(r_{1, i}\right)$ of an appliance (i), the generated wastewater volume or discharge of the appliance $\left(\mathrm{V}_{\mathrm{i}}\right)$, and the duration of use will be dealt with as normally distributed random variables.

The volume of an appliance (i) by a user profile (1), $V_{1, i}$, is expressed by a random value that represent the normal probability of water use of a certain appliance. The expected number of people $\mathbf{E}(\mathbf{n})_{\mathbf{l}, \mathbf{i}, \mathbf{t}}$ over a time $\Delta \mathrm{t}$ times the volume $\mathrm{V}_{\mathrm{l}, \mathrm{i}}$ gives the total volume over $\Delta \mathrm{t}$ which is the discharge $\mathrm{Q}_{1, \mathrm{i}}$, eqn. (6)

$$
\begin{aligned}
Q_{l, i, t} & =\left(r_{l, i}\right) \frac{E(n)_{L, i, t}}{\Delta t}\left(V_{l, i}\right)=E(n)_{L, i, t}\left(\frac{V_{l, i}}{\Delta t}\right)=E(n)_{L, i, t}\left(q_{l, i}\right) Q_{l, i, t}= \\
\left(r_{l, i}\right) \frac{E(n)_{L, i, t}}{\Delta t}\left(V_{l, i}\right) & =E(n)_{L, i, t}\left(\frac{V_{l, i}}{\Delta t}\right)=E(n)_{L, i, t}\left(q_{l, i}\right)
\end{aligned}
$$

The unit wastewater discharge generated during $\Delta \mathrm{t}$ at time of the day $(\mathrm{t})$ by category (1) when using a single appliance (i), will be summed up to account for other appliances $(i=1,2, . . j)$ and community categories $(1=1,2, \ldots \mathrm{k})$, eqn. (7).

$$
Q_{d, t}=\sum_{i=1}^{j} \sum_{L=1}^{k} Q_{L, i, t}
$$




\section{Case study: Dyar Al Rabwa - Sharm El Shiekh - Egypt}

The developed model to predict synthetic wastewater hydrograph will be applied for a case study: Dyar Al Rabwa (DAR) which is located in Sharm Al Sheikh South Sinai- Egypt. The community has an area of about 97,500 $\mathrm{m}^{2}$ (23 acres). The community is mostly composed of villas and under construction hotel. Dyar Al Rabwa is a predominately middle-class residential compound, and its residents are mostly Egyptians with very few foreigners. The wastewater hydrographs generated by the community were measured in the period from $23^{\text {rd }}$ of June till the $7^{\text {th }}$ of July 2011 (Figure 3).

\subsection{Community composition}

DAR has a total population $\mathrm{P}$ of 950 capita. The community consists of five social categories $(\mathrm{k}=5)$ with similar water use patterns, as shown in Figure 3.

\subsection{Synthetic water use patterns}

Water use patterns were synthesized for the various social categories (1), and the type of day (d) based on the working style of the users, the neighbourhood characteristics, the installed water facilities, and the published typical use patterns by individuals.

\subsubsection{Week day}

The synthesized water use patterns for the five main social categories forming the DAR community are graphed in Figures 4, 5, and 6 for three appliances (WC, wash basins, showers) respectively. The times of use, frequency of use per day are set to reflect the use of facilities on working day by them. The use of the kitchen sink and washing machines are assigned to both the stay-home and working woman, but with different use patterns as shown in Figures 7 and 8.

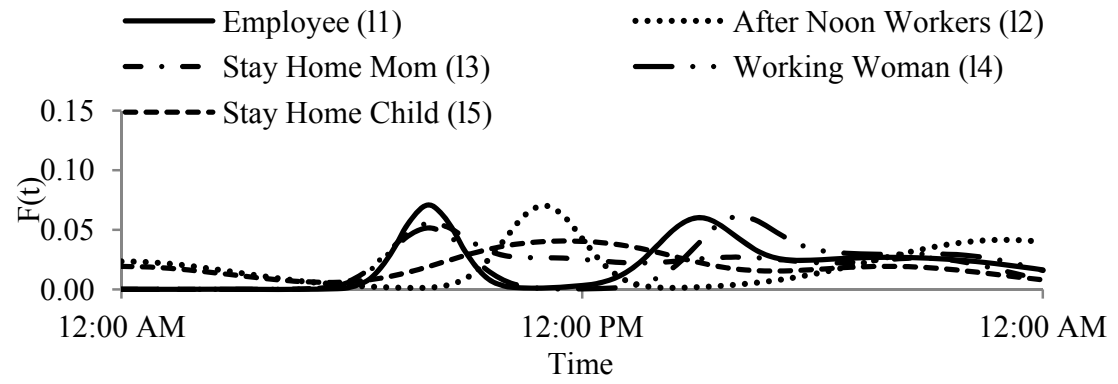

Figure 4: $\quad$ Probability distribution $\mathrm{f}(\mathrm{t})$ of using WC for different user types(l) on a weekday. 


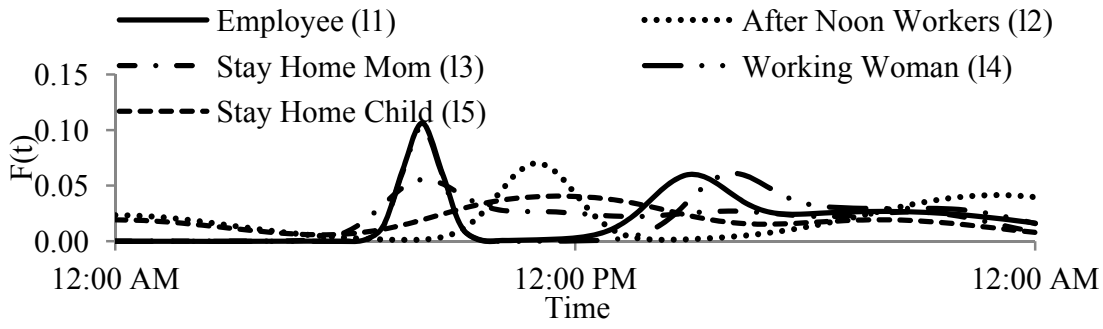

Figure 5: $\quad$ Probability distribution $\mathrm{f}(\mathrm{t})$ of using Basin for different user types(l) on a weekday.

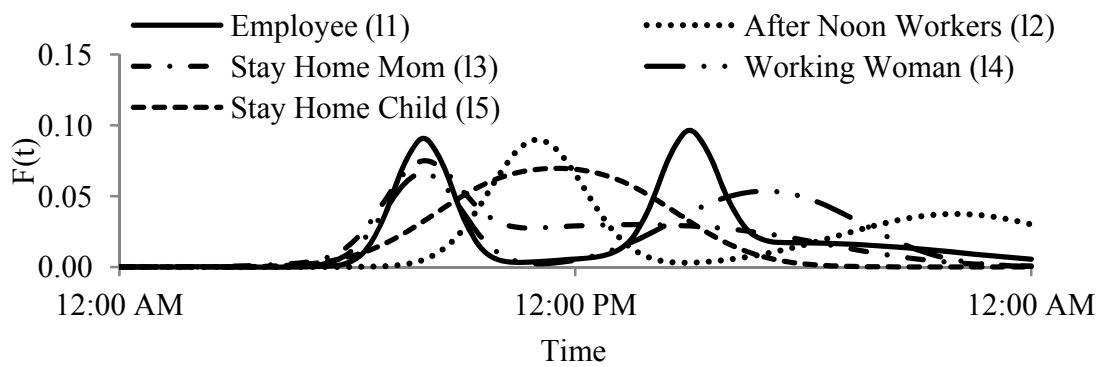

Figure 6: Probability distribution $\mathrm{f}(\mathrm{t})$ of using shower for different user types(1) on a weekday.

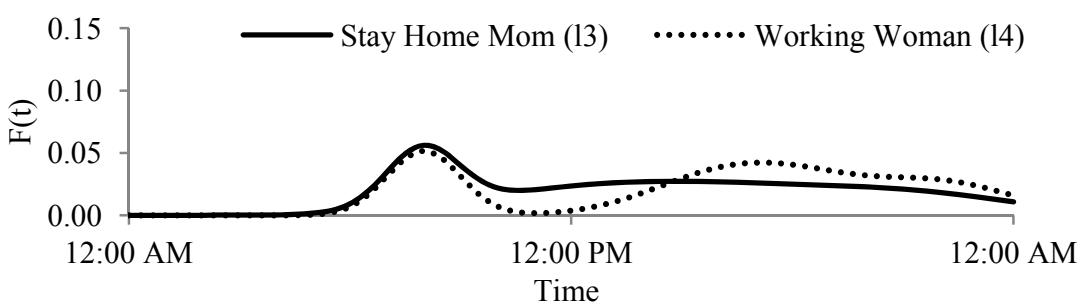

Figure 7: $\quad$ Probability distribution $\mathrm{f}(\mathrm{t})$ of using Sink for different user types(l) on a weekday. 


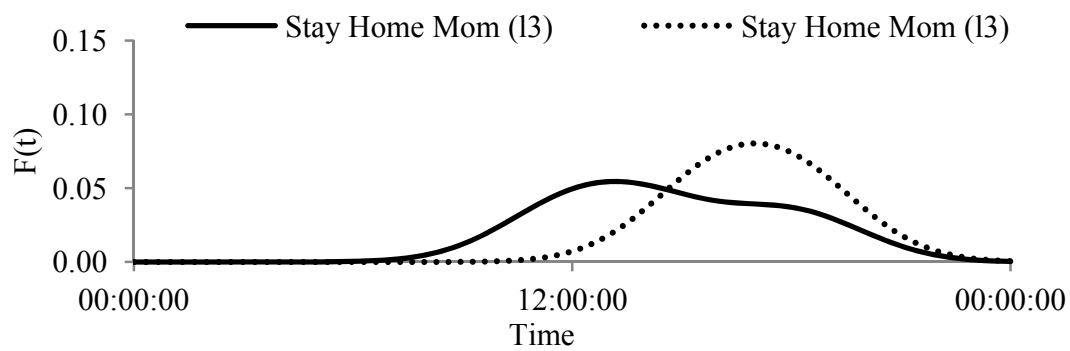

Figure 8: $\quad$ Probability distribution $\mathrm{f}(\mathrm{t})$ of using Washing machine for different user types(l) on a weekday.

\subsubsection{Week end}

The water use patterns for the various social categories are assumed to reflect that these days are non-working ones. The water use patterns, as shown in Figures 9, 10, and 11, reflect the human activities of the family members during these days and are much related to the cultural and religious factors. It is to be noted that certain social categories which have different use patterns during the weekdays may have similar use patterns during weekends.

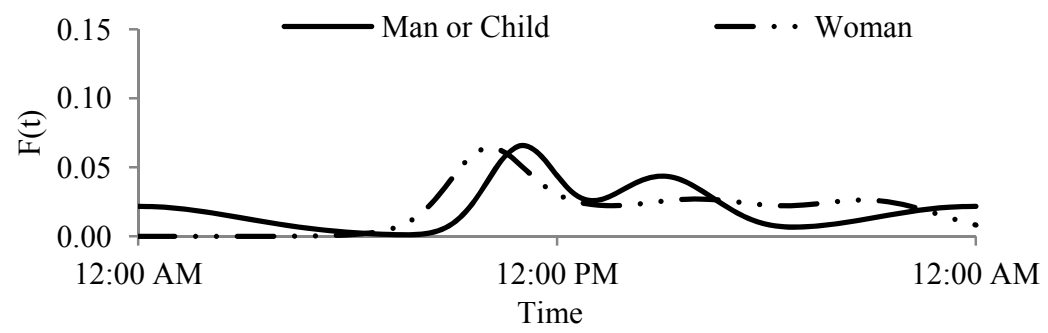

Figure 9: $\quad$ Probability distribution $\mathrm{f}(\mathrm{t})$ of using $\mathrm{WC}$ for different user types(l) on a weekend.

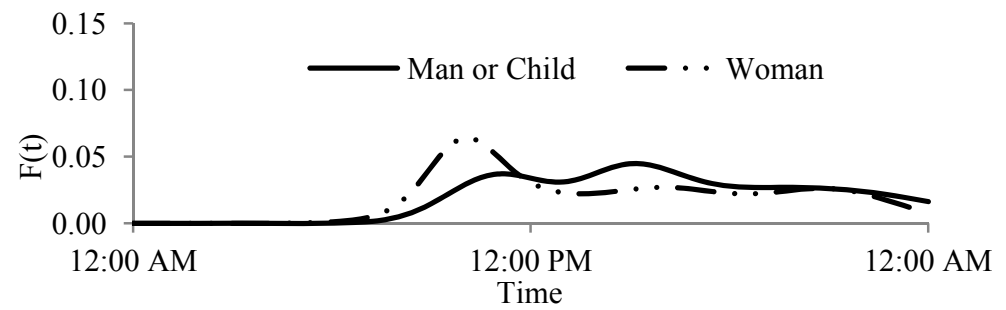

Figure 10: Probability distribution $\mathrm{f}(\mathrm{t})$ of using Basin for different user types(l) on a weekend. 


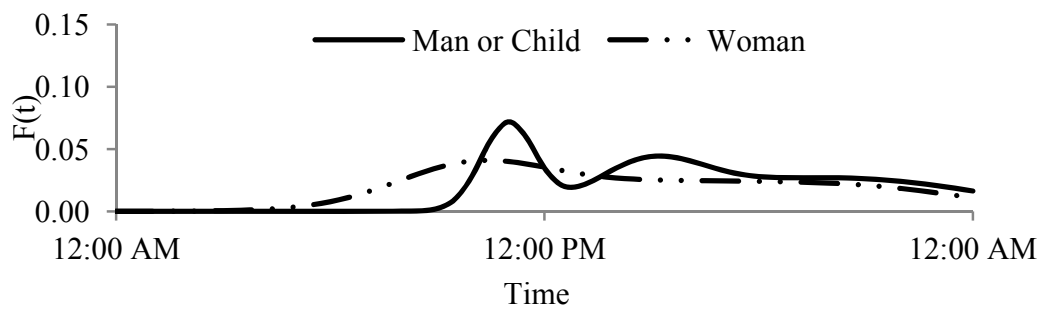

Figure 11: Probability distribution $\mathrm{f}(\mathrm{t})$ of using shower for different user types(l) on a weekend.

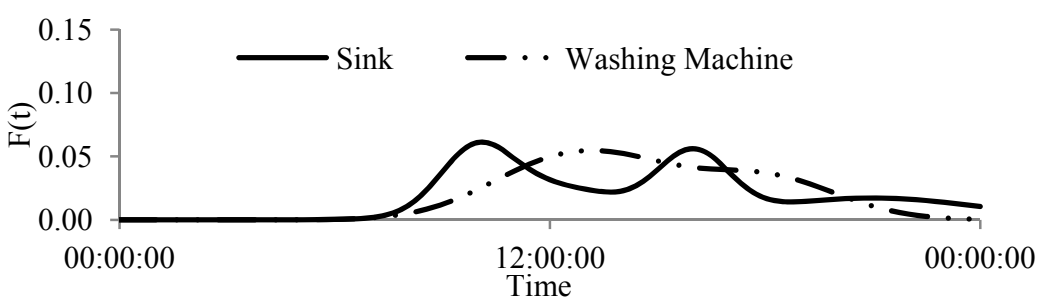

Figure 12: Probability distribution $\mathrm{f}(\mathrm{t})$ of using sink and washing machine for different user types(l) on a weekend.

\subsection{Unit generated wastewater volumes and frequency of use}

Tables 1 and 2 give the model default values used in this model based on limited survey done for the study area.

Table 1: $\quad$ Volumes per use (V) of different appliances (i).

\begin{tabular}{|c|c|c|}
\hline Appliance & Mean Volume (V, Liters) & $\begin{array}{c}\text { Standard deviation Volume } \\
\text { (Liters) }\end{array}$ \\
\hline WC & 12 & 4 \\
\hline Basin & 6 & 2 \\
\hline Shower & 100 & 10 \\
\hline Sink & 7 & 10 \\
\hline Washing machine & 20 & \\
\hline
\end{tabular}


Table 2: $\quad$ Frequency of use (r) of different water appliances (i) by different user types (1).

\begin{tabular}{|l|c|c|c|c|c|}
\hline \multicolumn{1}{|c|}{ Appliance } & $\begin{array}{c}\text { Employee } \\
(11)\end{array}$ & $\begin{array}{c}\text { After Noon } \\
\text { Workers(12) }\end{array}$ & $\begin{array}{c}\text { Stay Home } \\
\text { Mom (13) }\end{array}$ & $\begin{array}{c}\text { Working } \\
\text { Woman (14) }\end{array}$ & $\begin{array}{c}\text { Stay Home } \\
\text { Child (15) }\end{array}$ \\
\hline WC (i1) & 4 & 4 & 4 & 4 & 4 \\
\hline Basin (i2) & 6 & 6 & 6 & 6 & 6 \\
\hline Shower (i3) & 0.75 & 0.75 & 0.75 & 0.75 & 0.75 \\
\hline Sink (i4) & $\mathrm{X}$ & $\mathrm{X}$ & 3 & 3 & $\mathrm{X}$ \\
\hline $\begin{array}{l}\text { Washing } \\
\text { machine (i5) }\end{array}$ & $\mathrm{X}$ & $\mathrm{X}$ & 0.2 & 0.2 & $\mathrm{X}$ \\
\hline
\end{tabular}

\subsection{Measured and predicted hydrographs}

Wastewater hydrographs generated from the entire DAR community during weekdays were derived by the model for different probability of non-exceedance as shown in Figure 13. A comparison between the measured hydrographs and those synthesized by the model for weekdays is shown in Figure 14. The

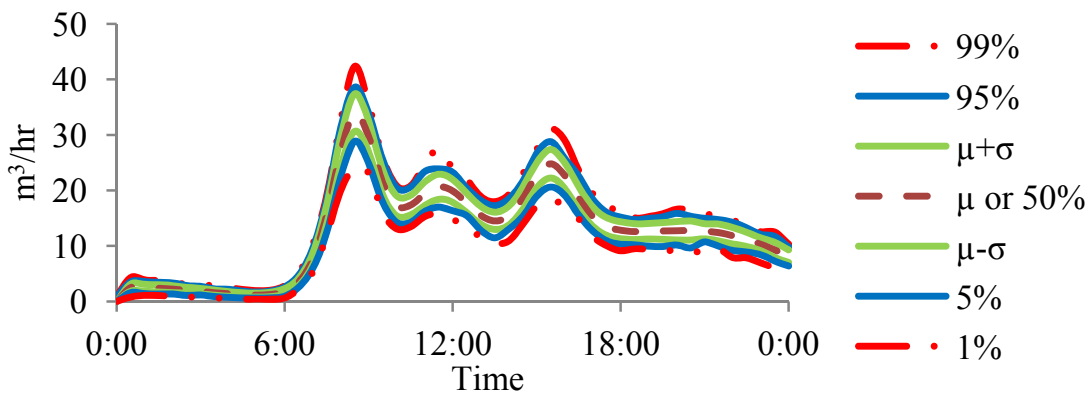

Figure 13: Envelope hydrographs for different probabilities of non-exceedance for a weekday.

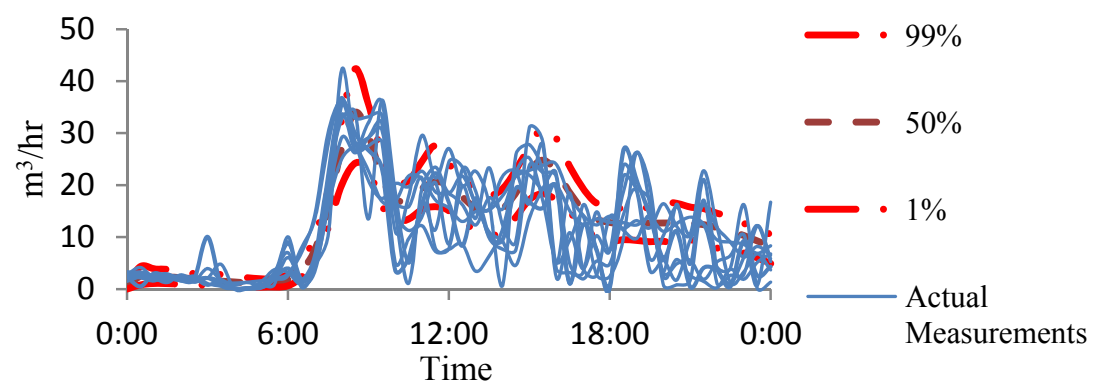

Figure 14: Actual hydrographs versus model envelope probability hydrographs for a weekday. 


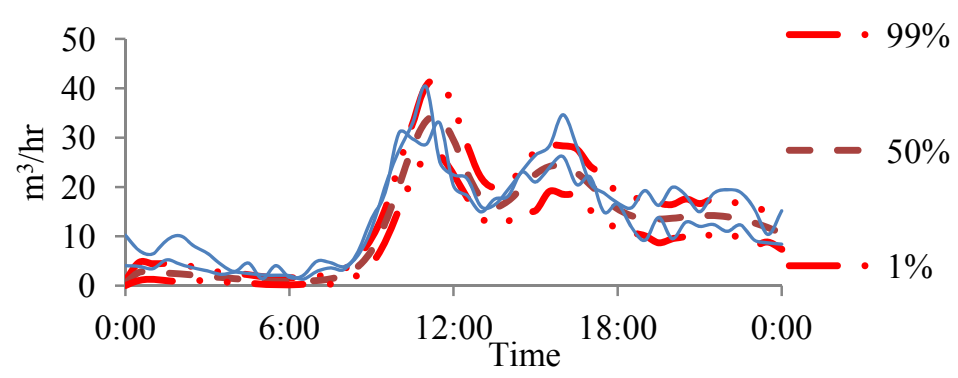

Figure 15: Measured hydrographs versus model envelope probability hydrographs for a weekend.

predicted wastewater discharges are within the same range of those measured. The deviations may be attributed to the assumed water use patterns and to what extent they resemble the actual use patterns for the community. Figure 15 compares the synthesized and measured weekend wastewater hydrographs for DAR. It is to be noted that a better agreement can be observed for the weekend.

\section{Conclusions and recommendations}

The developed model can generate synthetic domestic wastewater hourly flow hydrographs based on the specific socioeconomic characteristics of small arid communities. The hourly hydrographs are generated for weekdays and weekends. The synthetic hydrographs are developed while retaining their commonly observed random behaviour. The socioeconomic characteristics of a community is accounted for by the composition of the community of its social categories, the water use pattern of every category during the various daily activities (weekday, weekend, special event), and the water use facilities (fixtures and appliances) available to the community. The model utilizes different water use patterns by every social group for every appliance during the different types of days. The use patterns account for the stochastic nature of use in terms of number of uses, duration of the use and times of use in the day. Randomly generated hydrographs are generated for weekdays and weekends along with synthetic hydrographs of non-exceedance. The model was verified for a small residential compound in Sharm El Shiekh - Egypt using 11 days of flow measurements performed in summer. The synthetic hydrographs based on assumed water use patterns of the various members of the community compared reasonably with the measured hydrographs. The synthetic hydrographs can be derived for a community under consideration to reflect its socioeconomic conditions and thus can be used to generate probability based peaking factors to be used in the design of sewerage systems pumping facilities, and treatment plants. 


\section{Acknowledgements}

\section{Credits}

This publication is based on a collaborative research project supported by Award No. C0015, from King Abdullah University of Science and Technology (KAUST), KSA.

\section{Authors}

Haitham Elnakar is Graduate Research Assistant at the Environmental Engineering Program at The American University in Cairo - AUC, and is working towards Master of Science in Environmental Engineering. Emad Imam is a Professor of Environmental Hydraulics at the department of Construction and Architectural Engineering. Khaled Nassar is an Associate Professor of Construction Engineering at the same department.

\section{References}

[1] Alberta Environmental Protection Standards and Guidelines, Edmonton, Alta:: Alberta Environment, Environmental Assurance Division, Environmental Policy Branch, Drinking Water Branch, 2006.

[2] Environmental Protection Agency (EPA) Process Design Manual. Wastewater Treatment Facilities for Sewered Small Communities. Cincinnati, Ohio, 1977.

[3] Geyer, J. C., and Lentz, J. J., An Evaluation of the Problems of Sanitary Sewer System Design, Baltimore: Dept. of Sanitary Engineering and Water Resources, Johns Hopkins University, 1964.

[4] Butler, D., and Graham, N. J. D., Modeling Dry Weather Wastewater Flow in Sewer Networks", Journal of Environmental Engineering, Vol. 121, No. 2, pp. 161-173, 1995.

[5] Butler, D., A Small-Scale Study of Wastewater Discharges from Domestic Appliances, Water and Environment Journal, Vol. 5, Issue 2, pages 178184, April 1991.

[6] Imam, E., Elnakar, H. Design Flow Factors for Sewerage Systems in Small Arid Communities, Proc. of The 2011 International Conference on Water, Energy, and the Environment, ICWEE 2011, Sharjah, United Arab Emirates, pp. 266-272, 2011. 